\title{
Effects of hyperbaric oxygen therapy combined with platelet-rich plasma on diabetic wounds: an experimental rat model
}

\author{
Gündüz Yümün ${ }^{1}$, Cüneyt Kahraman², Nail Kahraman³, Ulviye Yalçınkaya ${ }^{4}$, Aydin Akçılar, \\ Engin Akgül6, Ahmet Hakan Vural ${ }^{6}$
}

\author{
${ }^{1}$ Department of Cardiovascular Surgery, Medical School, Namik Kemal University, \\ Tekirdag, Turkey \\ ${ }^{2}$ Department of Internal Medicine, Medical School, Dumlupinar University, Kütahya, \\ Turkey \\ ${ }^{3}$ Department of Cardiovascular Surgery, Bursa Yuksek Ihtisas Hospital, Bursa, Turkey \\ ${ }^{4}$ Department of Pathology, Medical School, Uludag University, Bursa, Turkey \\ ${ }^{5}$ Laboratory Animal Research Center, Medical School, Dumlupinar University, Kütahya, \\ Turkey \\ ${ }^{6}$ Department of Cardiovascular Surgery, Medical School, Dumlupinar University, \\ Kütahya, Turkey
}

Submitted: 14 November 2014

Accepted: 24 January 2015

Arch Med Sci 2016; 12, 6: 1370-1376

DOI: 10.5114/aoms.2016.62905

Copyright $\odot 2016$ Termedia \& Banach

\section{Abstract}

Introduction: Hyperbaric oxygen and platelet-rich plasma are used in the treatment of diabetic wounds. The aim of this study is to evaluate the effects of hyperbaric oxygen therapy and autologous platelet concentrates in healing diabetic wounds.

Material and methods: Thirty-six female Wistar albino rats were used in this study. Diabetes mellitus was induced chemically with an intraperitoneal injection of streptozotocin. The rats were divided into a control group, a hyperbaric oxygen group, a platelet-rich plasma group, and a combined therapy group. Platelet-rich plasma was applied just after the creation of the wound; hyperbaric oxygen treatment was carried out daily over 7 days. Wound healing was evaluated according to four parameters: ulcerations, epidermal thickness, density of dermal collagen fibers, and proliferation of dermal blood vessels.

Results: The number of active ulcers in the combined therapy group was fewer than in the control group $(p=0.039)$, and the wound area was greatest in controls $(p<0.001)$. The epidermal thickness in platelet-rich plasma and combined therapy groups was non-significantly greater than in the control group ( $p=0.097$ and $p=0.074$, respectively). The amount of fibrous collagen in these two groups was greater than in the control group $(p=0.002)$. Conclusions: Combined hyperbaric oxygen and platelet-rich plasma therapy was found to be successful in diabetic wound healing. The combination therapy had no additive effect in terms of angiogenesis and the development of new collagen fibers.

Key words: hyperbaric oxygen, platelet-rich plasma, combination therapy.

\section{Introduction}

Diabetic wounds are a common complication in diabetic patients and can lead to amputation [1,2]. Diabetic wound healing is impaired by

\author{
Corresponding author: \\ Gündüz Yümün \\ Department of \\ Cardiovascular Surgery \\ Namik Kemal University \\ Medical School \\ Tekirdag, Turkey \\ Phone: +90 5547996341 \\ E-mail: gunduzyumun@gmail. \\ com
}


such causes as lack of growth factors, angiogenesis failure, and microvascular disorders [3, 4].

In recent years, numerous studies have been reported that describe the beneficial effects of platelet-rich plasma (PRP) and hyperbaric oxygen (HBO) on diabetic wound healing $[5,6]$. Platelet-rich plasma contains high levels of factors that act on wound healing, such as platelet-derived growth factor, transforming growth factor- $\beta$, insulin-like growth factor-I, vascular endothelial growth factor, and basic fibroblast growth factor $[5,6]$. Local antibiotic applications and surgical revascularization have been found beneficial in wound healing of diabetic patients [7, 8].

The role of $\mathrm{HBO}$ in wound healing is multifactorial. Oxygen consumption is increased as leukocytes migrate to the wounded area, while fibroblast activity leads to collagen deposition and collagen synthesis in a healing wound [9]. Accumulation of high oxygen at the wound site leads to neovascularization by stimulating both bone marrow and endothelium [10, 11]. Although numerous studies have investigated $\mathrm{HBO}$ and PRP methods, no study of diabetic wound healing to date has included hyperbaric oxygen therapy combined with platelet-rich plasma.

We aimed to investigate the advantages and side effects of hyperbaric oxygen therapy combined with PRP as a treatment for diabetic wounds.

\section{Material and methods}

This study was approved by the local animal research ethics committee. Rats were housed singly in approved polycarbonate cages and were kept at a controlled temperature $\left(23 \pm 2^{\circ} \mathrm{C}\right)$ and humidity $(55 \pm 5 \%)$ under an artificially controlled light cycle. Food and water were given ad libitum. The experiment was done in accordance with the previous study [12].

Thirty-two female Wistar rats were divided into four groups: a diabetic control group, a hyperbaric oxygen group, a platelet-rich plasma group, and a combined therapy group (PRP + HBO).

\section{Induction of diabetes mellitus}

Rats were fasted overnight before being injected intraperitoneally (i.p.) with streptozotocin (STZ) at a dose of $55 \mathrm{mg} / \mathrm{kg}$ body weight (in $0.1 \mathrm{M}$ citrate buffer, $\mathrm{pH}$ 4.5). Blood glucose levels were measured daily with a glucometer (Accu-Chek Active, Roche Diagnostics, Germany) to confirm the development of diabetes. Only those animals that showed hyperglycemia (blood glucose level $>250 \mathrm{mg} / \mathrm{dl}$ ) were considered to be diabetic [12]. If the glucose level was under $250 \mathrm{mg} / \mathrm{dl}$, then the STZ dose was repeated.

\section{Wounding procedures}

Diabetic rats were anesthetized by intraperitoneal injection of xylazine hydrochloride $(10 \mathrm{mg} /$ $\mathrm{kg}$ ) and ketamine hydrochloride $(25 \mathrm{mg} / \mathrm{kg})$, and their dorsal surface hair was trimmed with an electric clipper. A full-thickness wound was created in the interscapular region of the upper back of each rat with a punch biopsy instrument (diameter $6 \mathrm{~mm}$ ). After the application of PRP (if applicable), the wound was closed (Figures $1 \mathrm{~A}, \mathrm{~B}$ ).

\section{Preparation of platelet-rich plasma}

Platelet-rich plasma was prepared from the blood of 4 rats. The donor rats were anesthetized and their blood was collected by cardiac puncture under anesthesia. Sixty $\mathrm{ml}$ of blood was added immediately to an anticoagulant. A citrate phosphate dextrose buffer $(0.15 \mathrm{mg}$ of $1 \mathrm{ml}$ citrate phosphate dextrose buffer (CPD)) was added in the ratio of $1 \mathrm{ml}$ of CPD buffer to $5 \mathrm{ml}$ of blood. The blood was then centrifuged at $1200 \mathrm{rpm}$ for 4 min using the Smart PreP Concentrate System (Harvest Technologies, Germany). The precipitate containing PRP was used for a second centrifugation at $3700 \mathrm{rpm}$ for $10 \mathrm{~min}$. The PRP was applied into the wound and the wound was closed.

\section{Hyperbaric oxygen procedure}

Hyperbaric oxygen sessions were conducted using an experimental hyperbaric chamber (AN -
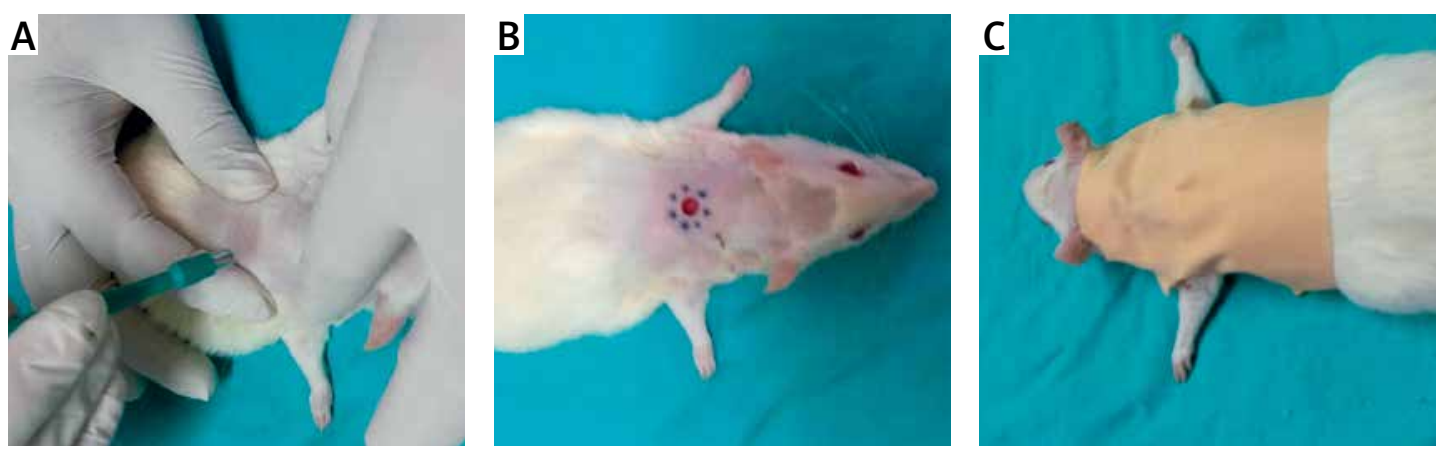

Figure $1 \mathrm{~A}-\mathrm{C}$. Creation and closing of the wound 
500, Sechrist, USA). The sessions were conducted daily and began on the first post-operative day; 8 animals were treated at the same time for $90 \mathrm{~min}$ at $3 \mathrm{~atm}$ absolute pressure [7, 9]. We opted for 7 sessions in the $\mathrm{HBO}$ and PRP + HBO groups. The beginning of the session included a compression period. After $15 \mathrm{~min}$, the chamber manometer indicated $3 \mathrm{~atm}$. This pressure (3 ATA) was maintained for $60 \mathrm{~min}$, followed by decompression for $15 \mathrm{~min}$; thus, each session ended after $90 \mathrm{~min}$.

\section{Complete blood count}

All rats were anesthetized after the treatment procedures on the $8^{\text {th }}$ day and their blood was collected by cardiac puncture under anesthesia. A complete blood count was then done for each rat using Coulter Gen-S automated hematology instruments (Beckman Coulter LH 780 Gen-S System; Miami, FL, USA).

\section{Histologic analysis}

All rats were euthanized by intraperitoneal injection of pentobarbital (200 mg) on day 8 . Each ulcer was harvested with surrounding tissue using sterile surgical scissors. The sample was fixed overnight in $10 \%$ buffered formalin solution. Each sample was then cut through at the widest margin and embedded in paraffin. Samples were sectioned in 4- $\mu \mathrm{m}$ increments. For each wound, three serial sections were placed on a slide and stained with hematoxylin and eosin (HE), Masson's trichrome, and CD34 (1: 75, Leica, England). Under light microscopy, the sections were photographed using an upright bright field microscope equipped with a color camera (Figures 2 A-D).

\section{Assessment of wound healing}

To evaluate wound healing, the wound surface area, the presence or absence of an ulcer, epidermal thickness, dermal collagen fiber density, and proliferation of dermal blood vessels were considered.

Epidermal tackiness: HE-stained sections were used for the evaluation of the wound surface, the presence of ulcerations, and epidermal thickness. Epidermal thickness was classified by comparison with intact epithelium around the wound. The presence of a wound was also recorded.

Dermal collagen: To assess the state of the dermal collagen fibers, Masson trichrome-stained sections were evaluated. The amount of dermal collagen was classified as normal, increased, or decreased.

Dermal vessels: The density of dermal blood vessels was examined in the sections stained with CD34 antibody on the autostainer (Leica BONDMAX, Bannockburn, IL, USA) using a multimer DAB kit. Neovascularization was classified as normal, mildly increased, moderately increased, or severely increased.

Wound area measurement: Photographs were taken of wound sites and wound sizes were measured via the 'netcad' digital imaging analysis program (S.NO:125478BD, Ankara, Turkey) (Figure 3). Mean wound sizes are shown in Table I.

\section{Statistical analysis}

Results were summarized using descriptive statistics. The variables were expressed as numbers and class for categorical variables and mean \pm standard deviation (or median and range for continuous variables) according to the distribution of the data. Categorical data were compared with the $\chi^{2}$ test or Fisher's exact test. Normally distributed data were compared using Student's $t$ test and the Tukey test, while data with a skewed distribution were compared using the Mann-Whitney test. Correlation analysis was done using Pearson's test. The difference was considered statistically significant if $p<0.05$. All statistical analyses were performed using SPSS 18 (SPSS Inc., Chicago, IL, USA) software.

\section{Results}

The study started with 36 female Wistar albino rats. Four of them were sacrificed for the preparation of PRP before treatment. The other 32 rats were randomly divided into four groups according to treatment protocols. At the end of the study, the rats' blood glucose levels and body weights were measured again. Weight loss was determined to be approximately $4 \%$. At the end of the treatment, the median blood glucose level was 302 (ranging from 251 to 506) $\mathrm{mg} / \mathrm{dl}$.

\section{Complete blood count}

At the end of the study all of the rats were anesthetized and their blood was collected by cardiac puncture; a complete blood count was then taken. The platelet count and reticulocyte distribution (RDW) were significantly higher in the control group than in other groups. The lymphocyte ratio was higher in the PRP group compared to other groups, but the difference was not statistically significant. Neutrophil count was higher in the hyperbaric oxygen group than in the other groups (Table I). There was a positive correlation between the wound area and both RDW $(R=0.701, p<0.001)$ and platelet count $(R=0.479, p=0.006)$.

\section{Histopathological analysis}

Active ulcers: Five $(62.5 \%)$ rats in the control group, $3(37.5 \%)$ in the HBO group, 2 (25\%) in the PRP and 1 in the combined group (12.5\%) were 

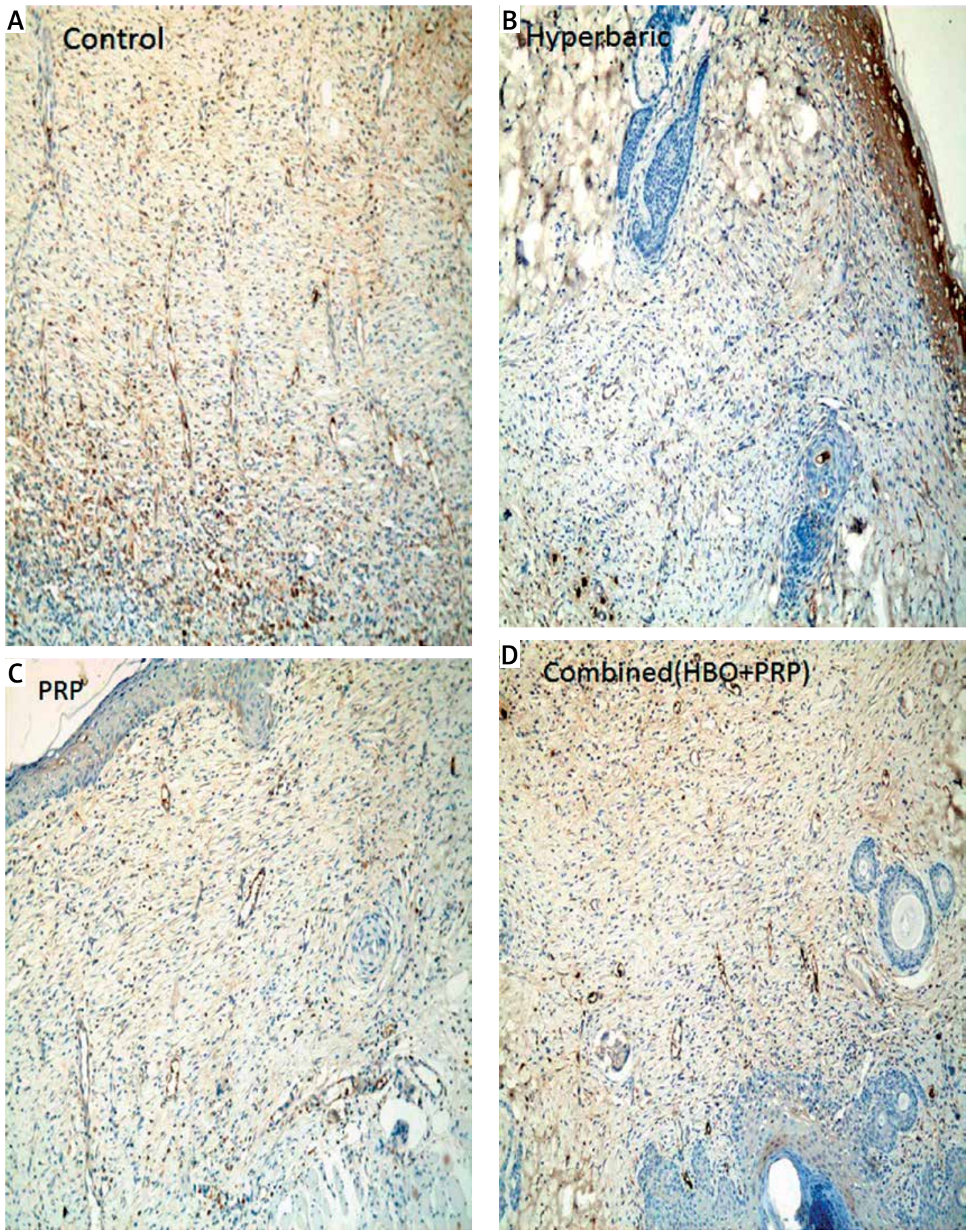

Figure 2. Angiogenesis is indicated by the blue color (CD34). Group microscopic images: A - control group, B - hyperbaric oxygen group, $\mathbf{C}$ - platelet-rich plasma group, $\mathbf{D}$ - combined group

detected to have active skin ulcers (Table II). The number of active skin ulcers in the combination therapy group was significantly lower than in the control group $(p=0.039)$.

Epidermal thickness: Epidermal thickness in the PRP and combined groups was greater than in the control group, but the differences between the groups were not statistically significant $(p=0.097$ and $p=0.074$, respectively).
Dermal collagen: In all the treatment groups compared to the control group, there was a significantly increased amount of dermal collagen in the wound area (Table II). The hyperbaric oxygen group, PRP, and combined therapy group were similar in the amount of dermal collagen $(p=0.119)$.

Dermal vessels: Dermal angiogenesis in the study was not statistically different among the 


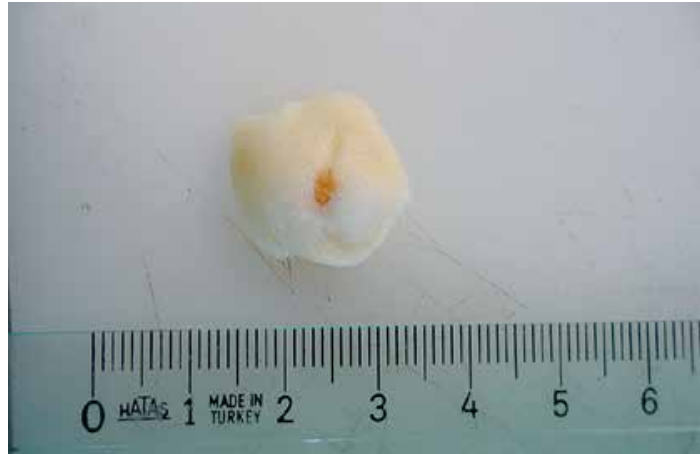

Figure 3. The wound excised with surrounding tissue and photographed for area measurement

four groups (Table II); however, angiogenesis was higher in all treatment groups compared to the control group, although the difference was not statistically significant $(p=0.65)$.

Wound area: Wound areas of all treatment groups were smaller than in the control group (Table II). The combined treatment group had the best results compared to the others (hyperbaric vs. combined: $p=0.002$; PRP vs. combined: $p=0.022)$. In the PRP group, wound area was smaller than in the hyperbaric oxygen group, but this difference was not statistical significant $(p=0.072)$.

A foreign body reaction was detected in 2 (25\%) rats in the PRP group, 2 (25\%) in the control group, and 3 rats (37.5\%) in the combined therapy group (Table II).

\section{Discussion}

In this study, the experimental diabetic wound model and treatment options were investigated. Hyperbaric oxygen treatment, platelet-rich plas$\mathrm{ma}$, and a combination of $\mathrm{HBO}$ and PRP were used as treatments in the study. The combination therapy was superior to the control group in terms of closing of the skin ulcer. However, combination therapy and separate therapies were similar in terms of angiogenesis and new collagen fiber development. All treatment options were successful in generating new collagen fibers and neovascularization.

Wound healing is a process in which cells, extracellular matrix, cytokines, and growth factors all have roles to play. Diabetes mellitus inhibits the three stages of wound healing: the inflammatory phase, the proliferative stage through suppression of collagen deposition, and formation of new vessels $[2,4,13]$. Accelerated bacterial growth leads to cytokine production and a prolonged inflammatory response. As a result, the extracellular matrix is destroyed by the metalloproteases and causes chronic wounds. In this study, in the diabetic control group the wound area changed little over the course of the study. Furthermore, the skin of the

Table I. Rats' characteristics before and after the trial

\begin{tabular}{|c|c|c|c|c|c|c|}
\hline Paramter & Control & PRP & HBO & Combined & Total & $P$-value \\
\hline \multicolumn{7}{|l|}{ Before the trial: } \\
\hline $\begin{array}{l}\text { Blood glucose } \\
{[\mathrm{mg} / \mathrm{dll}]}\end{array}$ & $92 \pm 9$ & $107 \pm 9$ & $98 \pm 6$ & $105 \pm 15$ & $99 \pm 11$ & 0.292 \\
\hline Body weight [g] & $242 \pm 9$ & $222 \pm 9$ & $228 \pm 13$ & $228 \pm 7$ & $228 \pm 13$ & 0.111 \\
\hline \multicolumn{7}{|l|}{ After the trial: } \\
\hline $\begin{array}{l}\text { Blood glucose } \\
{[\mathrm{mg} / \mathrm{dl}]}\end{array}$ & $299(260-387)$ & $286(251-360)$ & $356(265-506)$ & $305(254-357)$ & $302(251-506)$ & 0.128 \\
\hline Body weight [g] & $232 \pm 9$ & $220 \pm 6$ & $226 \pm 12$ & $222 \pm 9$ & $224 \pm 12$ & 0.222 \\
\hline Hemoglobin $[\mathrm{g} / \mathrm{dl}]$ & $13.8(13.3-14.3)$ & $13.5(12.2-15.2)$ & 13.9 & $13.7(13.4-14.6)$ & $13.7(12.2-15.2)$ & 0.489 \\
\hline RDW (\%) & $12.2(11.9-13.1)$ & $11.2(10.5-11.9)$ & $11.6(11.2-12.2)$ & $11.5(11.2-12)$ & $11.5(10.5-13.1)$ & 0.001 \\
\hline $\begin{array}{l}\text { Platelets } \\
{\left[\times 10^{3} / \mu \mathrm{ll}\right]}\end{array}$ & $1062(788-1694)$ & $669(244-839)$ & 769 (691-879) & $810(573-941)$ & $811(244-1694)$ & 0.011 \\
\hline $\begin{array}{l}\text { Leukocytes } \\
{\left[\times 10^{3} / \mu l\right]}\end{array}$ & $2.9 \pm 1.1$ & $4.7 \pm 2.8$ & $3.2 \pm 1.7$ & $3.1 \pm 2.4$ & $3.5 \pm 2.1$ & 0.506 \\
\hline $\begin{array}{l}\text { Lymphocytes } \\
{\left[\times 10^{3} / \mu l\right]}\end{array}$ & $2.28(1.15-290)$ & $4.66(0.14-7.6)$ & $2.38(0.52-4.30)$ & $2.61(0.52-6.71)$ & $2.61(0.14-7.6)$ & 0.086 \\
\hline $\begin{array}{l}\text { Neutrophils } \\
{\left[\times 10^{3} / \mu \mathrm{l}\right]}\end{array}$ & $0.1(0.04-0.3)$ & $0.18(0.03-0.2)$ & $0.5(0.01-1)$ & $0.16(0.06-0.24)$ & $0.25(0.03-1)$ & 0.005 \\
\hline $\begin{array}{l}\text { Wound area } \\
{\left[\mathrm{mm}^{2}\right]}\end{array}$ & $83.3 \pm 42.2$ & $29.1 \pm 9.9$ & $42.1 \pm 14.9$ & $17.6 \pm 7.5$ & $43.1(11-130)$ & $>0.001$ \\
\hline
\end{tabular}

PRP - platelet-rich plasma group, HBO - hyperbaric oxygen group, Combined - combined platelet-rich plasma and hyperbaric oxygen group, Control - diabetic control group, RDW - red blood cell distribution width. 
Table II. Histologic results according to treatment groups

\begin{tabular}{|c|c|c|c|c|c|c|c|}
\hline Parameter & Class & Control & PRP & HBO & Combined & Total & $P$-value \\
\hline \multirow{2}{*}{$\begin{array}{l}\text { Active skin } \\
\text { ulcer }\end{array}$} & Yes & $5(62.2 \%)$ & $2(25 \%)$ & $3(37.5 \%)$ & $1(12.5 \%)^{*}$ & $10(31.2 \%)$ & \multirow[t]{2}{*}{0.184} \\
\hline & No & $3(37.5 \%)$ & 7 (87.5\%) & $5(62.2 \%)$ & $7(87.5 \%)^{*}$ & $22(68.7 \%)$ & \\
\hline \multirow{3}{*}{$\begin{array}{l}\text { Epidermal } \\
\text { thickening }\end{array}$} & Thin & $5(62.2 \%)$ & $1(12.5 \%)$ & 3 & $1(12.5 \%)$ & $10(31.2 \%)$ & \multirow[t]{3}{*}{0.210} \\
\hline & Normal & - & $1(12.5 \%)$ & $2(25 \%)$ & $1(12.5 \%)$ & $4(12.5 \%)$ & \\
\hline & Thick & $3(37.5 \%)$ & $6(75 \%)$ & $3(37.5 \%)$ & $6(75 \%)$ & $18(56.2 \%)$ & \\
\hline \multirow{4}{*}{$\begin{array}{l}\text { Dermal } \\
\text { vessel }\end{array}$} & Normal & $1(12.5 \%)$ & $1(12.5 \%)$ & - & $1(12.5 \%)$ & $3(9.3 \%)$ & \multirow[t]{4}{*}{0.065} \\
\hline & Mildly increase & $4(50 \%)$ & - & $2(25 \%)$ & $2(25 \%)$ & $8(25 \%)$ & \\
\hline & Moderate increase & $3(37.5 \%)$ & $3(37.5 \%)^{\star}$ & $2(25 \%)$ & $4(50 \%)$ & $12(37.5 \%)$ & \\
\hline & Severe increase & - & $4(50 \%)^{*}$ & $4(50 \%)$ & $1(12.5 \%)$ & $9(28.1 \%)$ & \\
\hline \multirow{3}{*}{$\begin{array}{l}\text { Dermal } \\
\text { collagen }\end{array}$} & Decrease & 7 (87.5\%) & $1(12.5 \%)$ & $3(37.5 \%)$ & $1(12.5 \%)$ & $12(37.5 \%)$ & \multirow[t]{3}{*}{0.008} \\
\hline & Normal & - & $1(12.5 \%)$ & $2(25 \%)$ & - & $3(9.3 \%)$ & \\
\hline & Increase & $1(12.5 \%)$ & $6(75 \%)$ & $3(37.5 \%)$ & 7 (87.5\%) & $17(53 \%)$ & \\
\hline \multirow{2}{*}{$\begin{array}{l}\text { Foreign } \\
\text { body } \\
\text { reaction }\end{array}$} & Yes & $2(25 \%)$ & $2(25 \%)$ & 0 & $3(37.5 \%)$ & $7(21.8 \%)$ & \multirow[t]{2}{*}{0.254} \\
\hline & No & $6(75 \%)$ & $6(75 \%)$ & $8(100 \%)$ & $5(62.2 \%)$ & $25(78.1 \%)$ & \\
\hline
\end{tabular}

PRP - platelet-rich plasma group, HBO - hyperbaric oxygen group, Combined - combined platelet-rich plasma and hyperbaric oxygen group, Control - diabetic control group, *statistically significant difference compared to control group.

healed ulcers appeared to be abnormal when examined by light microscope.

Platelet-rich plasma stimulates wound healing via cytokines, growth factors, and chemotactic factors $[5,6,14]$. Wound closure with PRP also creates a suitable environment for wound healing and factors protect the wound to prevent an increase in microbial contamination as a result of healing.

In clinical trials with PRP, wound healing and organized collagen fiber density have been reported to increase, making PRP effective in diabetic foot wound healing and preventing amputation [15, 16]. On the other hand, a few studies have reported poor results of PRP in the treatment of venous ulcers $[17,18]$.

Lower extremity ulcer healing depends on many factors, including ischemia, edema, infection, poor glycemic control, nerve damage, and hemodynamic disorders [2, 3, 12, 19]. Hyperbaric oxygen therapy stimulates angiogenesis and fibroblast activity, and acts on leucocyte function to promote wound healing [20, 21]. Previous studies have demonstrated that in diabetic patients with peripheral artery disease, cutaneous microvascular reflexes become normal under hyperbaric oxygen conditions [22, 23].

Researchers recommend combination therapies in case of insufficient results from the separate treatments. The purpose of the combination therapy, in addition to the additive effects of different methods, is to obtain a synergistic effect. Neves et al. compared a control group to combined and separate PRP and HBO in the treatment of osteomyelitis in his experimental study. The combination therapy was reported as successful in terms of the activity of osteoblasts, osteocytes, and collagen [24]. In the present study, we found that separate treatments were useful for collagen fiber regeneration and dermal angiogenesis, but combination therapy was more successful for wound healing. The additive effect of combination therapy resulted in a decrease in the wound area and an increase in the amount of granulation. We did not note any side effects with the combination therapy of PRP and HBO.

In conclusion, the use of hyperbaric oxygen and platelet-rich plasma separately, or in combination, in the treatment of diabetic wounds was found to be safe and successful. In our experimental study, the advantage of PRP was its low cost and easy application. The combination therapy and separate therapies had effects in terms of angiogenesis and new collagen fiber development, but the combination therapy was more successful in wound closing. Clinical studies are now needed to compare the cost-effectiveness of the combination therapy.

\section{Conflict of interest}

The authors declare no conflict of interest.

\section{References}

1. Boulton AJ, Meneses P, Ennis WJ. Diabetic foot ulcers: a framework for prevention and care. Wound Repair Regen 1999; 7: 7-16. 
2. Ramsey S, Newton K, Blough D, et al. Incidence, outcomes, and cost of foot ulcers in patients with diabetes. Diabetes Care 1999; 22: 382-7.

3. Feener EP, King GL. Vascular dysfunction in diabetes mellitus. Lancet 1997; 350: 9-13.

4. Phillips TJ. Chronic cutaneous ulcers: etiology and epidemiology. J Invest Dermatol 1994; 102: 38S-41S.

5. Thom SR. Hyperbaric oxygen - its mechanisms and efficacy. Plast Reconstr Surg 2011; 127: 131-41.

6. Molloy T, Wang Y, Murrell G. Increased growth factors play a role in wound healing promoted by noninvasive oxygen-ozone therapy in diabetic patients with foot ulcers. Oxid Med Cell Longev 2014; 2014: 273475.

7. Varga M, Sixta B, Bem R, Matia I, Jirkovska A, Adamec M. Application of gentamicin-collagen sponge shortened wound healing time after minor amputations in diabetic patients - a prospective, randomised trial. Arch Med Sci 2014; 10: 283-7.

8. Inan B, Aydin U, Ugurlucan M, Aydin C, Teker ME. Surgical treatment of lower limb ischemia in diabetic patients long-term results. Arch Med Sci 2013; 9: 1078-82.

9. Valko M, Leibfritz D, Moncol J, et al. Free radicals and antioxidants in normal physiological functions and human disease. Int J Biochem Cell Biol 2007; 39: 44-84.

10. Gallagher KA, Liu ZJ, Xiao M, et al. Diabetic impairments in NO-mediated endothelial progenitor cell mobilization and homing are reversed by hyperoxia and SDF-1 alpha. J Clin Invest 2007; 117: 1249-59.

11. Goldstein LJ, Gallagher KA, Bauer SM, et al. Endothelial progenitor cell release into circulation is triggered by hyperoxia-induced increases in bone marrow nitric oxide. Stem Cells 2006; 24: 2309-18.

12. Mendes JJ, Leandro $\mathrm{Cl}$, Bonaparte DP, Pinto AL. A rat model of diabetic wound infection for the evaluation of topical antimicrobial therapies. Comp Med 2012; 62: 37-48.

13. Reiber GE. The epidemiology of diabetic foot problems. Diabet Med 1996; 13 Suppl 1: S6-11.

14. Eppley BL, Woodall JE, Higgins J. Platelet quantification and growth factor analysis from platelet-rich plasma: implications for wound healing. Plast Reconstr Surg 2004; 114: 1502-8.

15. Carter MJ, Fylling CP, Parnell LK. Use of platelet rich plasma gel on wound healing: a systematic review and meta-analysis. Eplasty 2011; 11: e38.

16. Carter CA, Jolly DG, Worden Sr CE, Hendren DG, Kane CJM. Platelet rich plasma gel promotes differentiation and regeneration during equine wound healing. Exp Mol Pathol 2003; 74: 244-55.

17. Senet P, Bon FX, Benbunan M, et al. Randomized trial and local biological effect of autologous platelets used as adjuvant therapy for chronic venous leg ulcers. J Vasc Surg 2003; 38: 1342-8.

18. Falanga V, Eaglstein WH, Bucalo B, et al. Topical use of human recombinant epidermal growth factor (h-EGF) in venous ulcers. J Dermatol Surg Oncol 1992; 18: 604-6.

19. Abidia A, Laden G, Kuhan G, et al. The role of hyperbaric oxygen therapy in ischaemic diabetic lower extremity ulcers: a double-blind randomised-controlled trial. Eur J Vasc Endovasc Surg 2003; 25: 513-8.

20. Hunt TK, Pai MP. The effect of varying ambient oxygen tensions on wound metabolism and collagen synthesis. Surg Gynecol Obstet 1972; 135: 561-7.

21. Tibbles PM, Edelsberg JS. Hyperbaric-oxygen therapy. N Engl J Med 1996; 334: 1642-8.

22. Siddiqui A, Davidson JD, Mustoe TA. Ischemic tissue oxygen capacitance after hyperbaric oxygen therapy: a new physiologic concept. Plast Reconstr Surg 1997; 99: 148-55.

23. Abidia A, Kuhan G, Bahia H, Chetter I, McCollum PT. Microvascular reflexes are influenced by oxygen in diabetic patients with peripheral arterial disease. $\mathrm{Br}$ J Surg 2001; 88: 749 .

24. Neves PC, Abib Sde C, Neves RF, et al. Effect of hyperbaric oxygen therapy combined with autologous platelet concentrate applied in rabbit fibula fraction healing. Clinics 2013; 68: 1239-46. 